\title{
A Hole in the Vacuum Hose of a Vehicle Provides Lower Differences in Brake Measurements by the Ministry of Transport Brake Testers Rather than the Characteristics of the Tester Used
}

\author{
Carolina SENABRE*, Sergio VALERO**, Emilio VELASCO**** \\ *Michael Hernández University, Mechanical Engineering Department, 03202, Elche, Spain, E-mail: csenabre@umh.es \\ **Michael Hernández University, Mechanical Engineering Department, 03202, Elche, Spain, E-mail: svalero@umh.es \\ ***Michael Hernández University, Mechanical Engineering Department, 03202, Elche, Spain, \\ E-mail: emilio.velasco@umh.es
}

cross $^{\text {ref }}$ http://dx.doi.org/10.5755/j01.mech.24.2.17752

\section{Introduction}

When your vehicle has to be tested by the Ministry of Industry, Tourism and trade of Spain (MOT), the procedure for the brake tests is carried out by placing the vehicle on rollers of the brake tester at any MOT station. This is indicated in the "MOT procedure manual" [1-4]. During the test, rollers rotate around $3-5 \mathrm{~km} / \mathrm{h}$ of speed, and then the driver brakes the vehicle by pressing the brake pedal until $100 \%$ of slippage of the vehicle is measured by the tester with a sensor placed between the rollers [5]. In previous researches the authors have been able to provide different brake data measurements obtained by different MOT brake testers [7]. Although all brake testers have the same rejection threshold to pass the brake exam, it has been demonstrated by the authors that different characteristics of MOT brake testers provides different brake data measurements [8].

To go one step further in this research it has been studied how a hole in the vacuum hose could modify brake measurements obtained in the MOT brake testers. The aim of this research is to know if a real problem in brake system of the car could vary the brake data measured and moreover if this variation of results is higher or lower than the variation of results that produce the characteristics of the MOT brake tester used.

Stopping sight distance is the distance travelled during the two phases of stopping a vehicle: perceptionreaction time (PRT), and manoeuvre time (MT) [1] "Perception-reaction time" is the time it takes for a road user to realize that a reaction is needed due to a road condition, decided what manoeuvre is appropriate (in this case, stopping the vehicle), and start the manoeuvre (taking the foot off the accelerator and depressing the brake pedal). "Manoeuvre time" is the time it takes to complete the manoeuvre (decelerating and coming to a stop). The distance driven during "perception-reaction time" and "manoeuvre time" is the "sight distance" needed. For a vehicle traveling at a constant rate, distance covered by a specific velocity and a certain perception-reaction time can be computed using simple dynamics:

$$
d_{r}=v t_{r}
$$

where: $d_{r}$ is the sight distance, $v$ is the velocity, $t_{r}$ is the perception-reaction time.
Then when the "Manoeuvre time" increases the sight distance also increases. Therefore, if it takes longer time to depressing the brake pedal the "sight distance" will increase.

A brake boosting system uses the depression caused by the suction in the intake manifold of an internal combustion engine to reduce the pressure to do on the brake pedal. The advantage of this system is that a softer push on the brake pedal is needed, but also a shorter braking distance. The vacuum servo or vacuum booster is attached between the master cylinder and the brake pedal.

This system assists the braking force to be applied on the brake pedal by the driver [9-10]. These boosting system consist on of a hollow housing with a rubber diaphragm, see item 6 from Fig. 1, in the middle to create two chambers that the pressure in both chambers of the unit is lowered when the engine is attached to the intake manifold of or the vacuum pump. And when brake pedal is applied a return spring keeps the diaphragm in the starting position, see item 11 from Fig. 1.

When the brake pedal is pushed it is opened an air valve, see item 5 from Fig. 1, to allow atmospheric pressure air to flow into the "supply" chamber of the booster. And when the pedal stops the air valve closes again. When a higher pressure is applied in one chamber, the diaphragm advances to the lower pressure chamber helped by a force created by the diaphragm and the differential pressure, this force helps to the driver's foot force. On the contrary, when there is none force applied on the pedal the air from the supply chamber flow toward from the vacuum chamber to the source of vacuum [10].

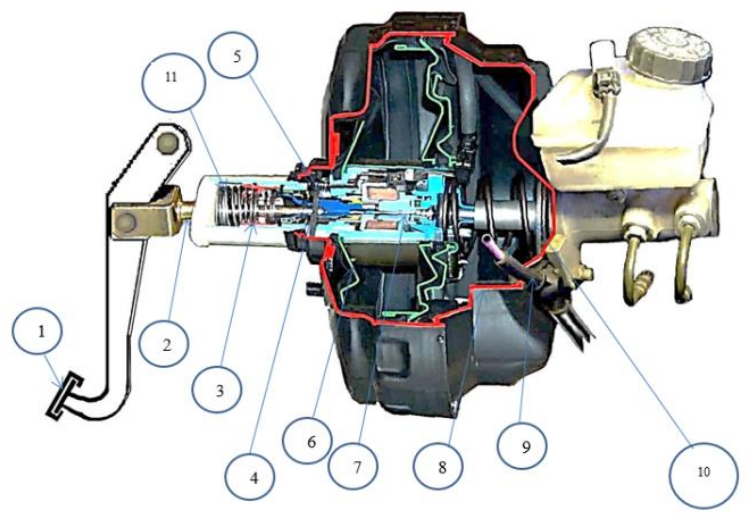

Fig. 1 Section of a Brake booster assembly 
Items from brake booster assembly of Fig. 1 are: 1 - brake pedal; 2 - brake pedal push rod; 3 - control valve; 4 - power piston; 5 - air valve; 6 - diaphragm; 7 - master cylinder push rod; 8 - outer shell; 9 - pipe; 10 - master cylinder; 11 - spring.

To boost the force applied by the pedal on to the master cylinder, see Fig. 1, the brake booster uses pump from the engine, this is a vacuum hose (Fig. 2) that moves the air throw a tube to help the movement of the cylinder. When the engine is not running the brake pedal is noted very hard, but when the booster air valve is opened it automatically push the master cylinder forward.

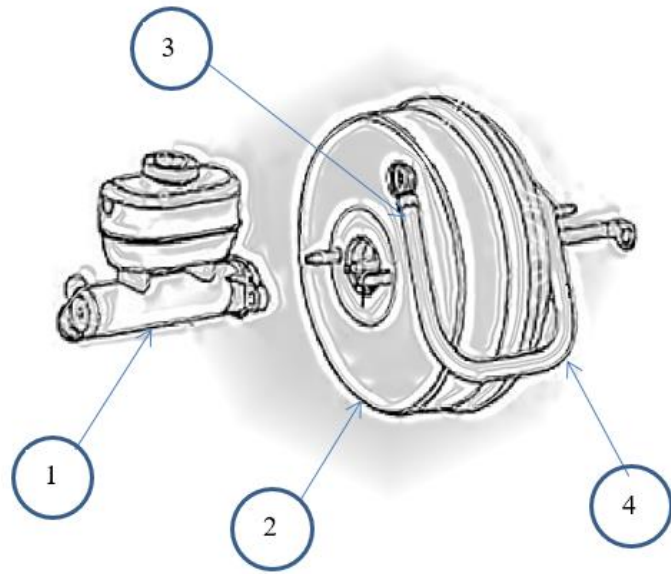

Fig. 2 External view of Brake boosting system

Items from brake booster assembly of Fig. 2 are: 1 - brake master cylinder; 2 - power brake boosterm; 3 - valve of brake booster.

\section{Experimentation}

For the experiment it was made a little hole in the vacuum hose of the brake booster to see if the MOT brake tester will provide different brake data.

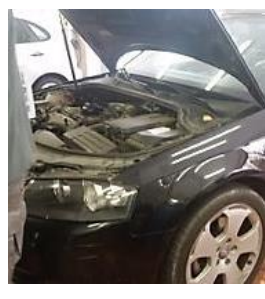

a

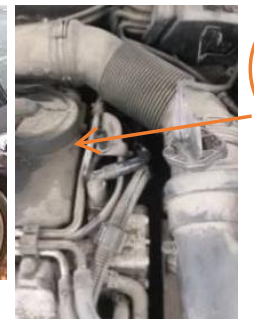

b

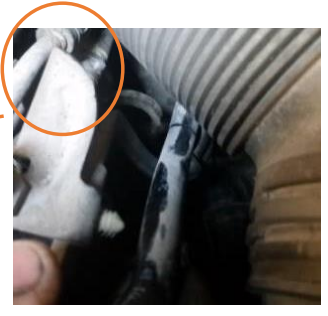

c

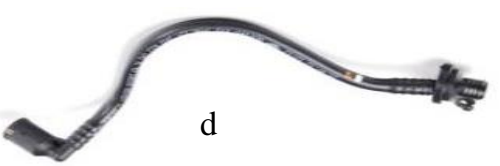

Fig. 3 The hole in hose to the brake boosting system: $a$ - view of the open car, $b$ - view of the inside of the vacuum servo system, c-the hole in the pipe or vacuum hose to the brake booster, $\mathrm{d}$ - the new vacuum hose

A problem in the vacuum booster could be checked pumping the brake pedal several times with the engine off to bleed off any vacuum that may still be in the unit. Then it was hold the foot on the pedal and start the engine. The booster was working, and then the amount of effort required holding the pedal dropped and the pedal itself depressed slightly. This means that the vacuum hose should be replaced.

When the vehicle is taken to the Ministry of Transport facilities the driver places the vehicle on the roller tester and depresses the brake pedal and he/she could not have mechanical information to know that the effort required holding the pedal dropped is higher than it should be.

Measurements obtained from the MOT brake tester from all tests were the brake force of each wheel to stop the vehicle [12-14]. Then, a PC calculates the total Efficiency of the vehicle brake system [6]. Finally, a comparative analysis of the braking data was obtained with three different Maha MOT testers, in order to compare if the brake tester characteristics provides higher differences in brake values rather than a hole in the vacuum hose of the brake system.

Although the roller roughness was the same in all MOT brake testers used, they had different distance between rollers and different roller diameter. Despite of having all MOT brake testers different characteristics, stablished by the MOT directive the directive 96/96 CEE [6], all of them have to measure the same minimum Efficiency of $50 \%$ to let the diver pass the test.

During all the experiments, all tyres had 2.2 bar tyre pressure. The characteristics of car remained also constant. Previous researches demonstrated that the variation of some parameters of the car produced a variation of brake data measures obtained from any brake tester.

\section{The minimum Efficiency of $50 \%$}

As stated in and the manual of MOT inspection of vehicles the minimum efficiency to pass the MOT parking brake test is $50 \%$ for vehicles [6,12-14].

The efficiency is:

$$
E=\frac{F_{\text {Total }}}{m g} 100
$$

where: $E$ is the $\%$ of efficiency, the minimum to pass the exam is $50 \%, F_{\text {total }}$ is the sum of braking forces of both wheels of both axis, $g$ is the acceleration of the gravity, $m$ is the maximum mass in $\mathrm{kg}$ permissible for the vehicle, in this case is:

$452 \mathrm{~kg}$ of vehicle weight $+75 \mathrm{~kg}$ of driver $=1527 \mathrm{~kg}$.

Load distribution is $60 \%$ for front axle:

$916,2 \mathrm{~kg}$ and $40 \%$ for rear axle $[7-10]=610,8 \mathrm{~kg}$.

The minimum brake force to be measured from each axis to pass the exam is calculated this way:

$$
\begin{aligned}
& F_{\text {front-axis }}=E \% \times \frac{m_{\text {front-axis }} g}{2_{\text {wheels }} \times 100} . \\
& F_{\text {front-axis }}=E \% \times \frac{916,2_{\text {front-axis }}}{2_{\text {wheels }} \times 100}=229,05 \mathrm{daN} .
\end{aligned}
$$




$$
F_{\text {rear-axis }}=50 \% \times \frac{610,8_{\text {rear-axis }}}{2_{\text {wheels }} \times 100}=152,7 \mathrm{daN} \text {. }
$$

To see if there are any variability of brake data measured due to the type MOT tester used, the vehicle, an AUDI A3, with 225/45 R17 V 91 tyres, was tested on three Maha testers (Figs. 4-6).

The Maha testers characteristic (Table 1).

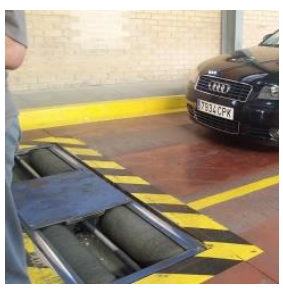

Fig. 4 MAHA IW2 RS5

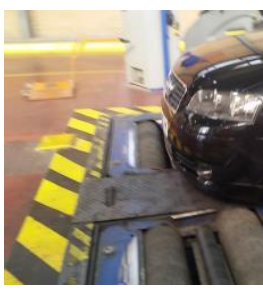

Fig. 5 MAHA IW7

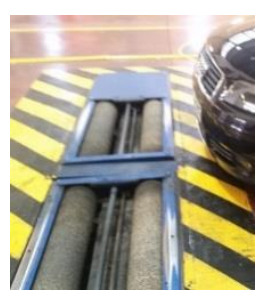

Fig. 6 MAHA

IW2 RS2

MBT 4000

Table 1
MAHA MOT Brake testers used for measurements

\begin{tabular}{|l|l|l|}
\hline Model & $\begin{array}{l}\text { Roller } \\
\text { diameter }\end{array}$ & $\begin{array}{l}\text { Distance between } \\
\text { rollers }\end{array}$ \\
\hline MAHA RS2 MBT 4000 & $202 \mathrm{~mm}$ & $430 \mathrm{~mm}$ \\
\hline MAHA IW7 MBT 7000 & $265 \mathrm{~mm}$ & $475 \mathrm{~mm}$ \\
\hline MAHA IW2 RS5 & $202 \mathrm{~mm}$ & $400 \mathrm{~mm}$ \\
\hline
\end{tabular}

The rugoses of the rollers surface on three MOT testers were the same.

The tester used to measure brake data with a hole in the brake hose was the Maha IW2 RS5. Fig. 7 provides daN of brake force of each wheel on three Mot brake testers.

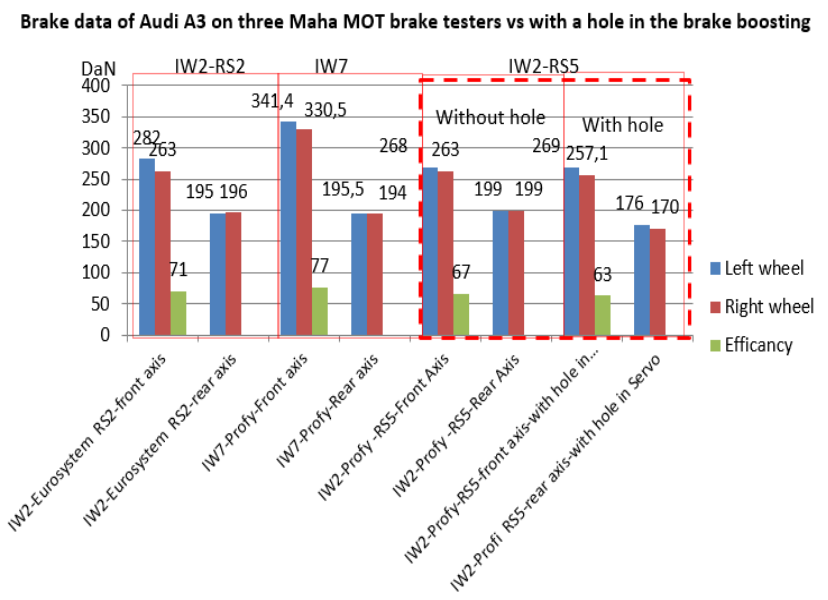

Fig. $7 \mathrm{DaN}$ of bake data on the Maha testers

It can be seen that the difference of Efficiency between the measurements taken with and without a hole in the vacuum hose on the same Maha brake tester IW2-RS5 is $4 \%$. This percentage is lower than differences of Efficiency obtained from Maha testers: IW2-RS5 and IW7, this is $10 \%$.

These differences between brake data obtained with the three Maha testers are due to the characteristics of tester. The parameters that vary from brake testers are: the distance between rollers, due to the variation of the angle $\theta$, and the variation of roller radius, $r_{r}$, when the roller roughness $\mu$ is the same, as it can be seen in the Fig. 8 and in the Eq. 2.

\section{Mathematical demonstration}

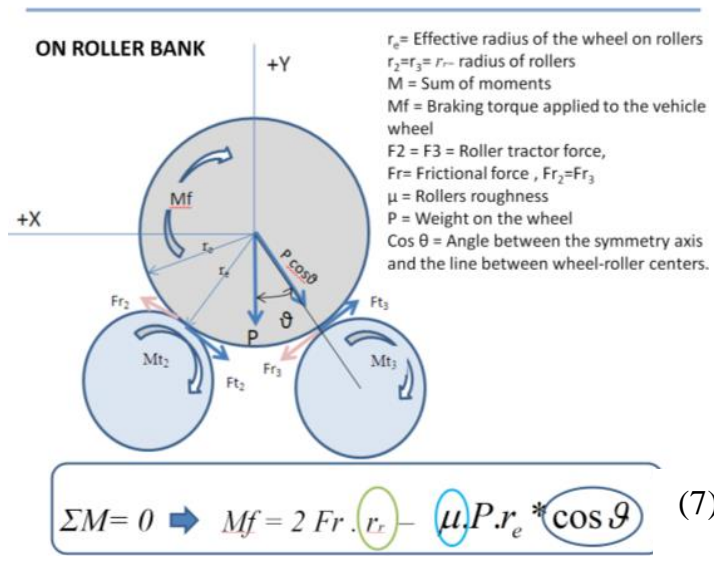

Fig. 8 Mathematical demonstration of the influence of the variation of parameter from the Maha testers

As it can be seen in Fig. 9, all brake forces measured from the front axis are higher than the minimum needed to obtain the $50 \%$ of Efficiency, therefore the vehicle a hole in the servo will also pass the brake test.

Although in all cases the vehicle will pass the exam, data obtained from the same brake tester with and without a hole in the vacuum hose are nearly the same, but different data are obtained when the car is tested on the other two Maha testers.

Thus, it can be said that differences of brake data measurements due to the tester characteristics are until $21,5 \%$ and difference due to the hole in the servo are until $2,2 \% \%$ in the front axle.

\section{DaN of brake force of the front axis of the vehicle Audi A3 measured on the three Mot Maha testers.}

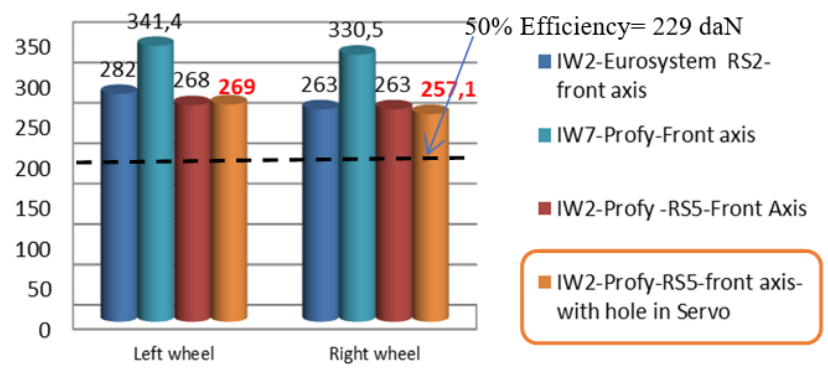

Fig. 9 DaN of brake force of the front axis of the vehicle measured on the three Mot Maha testers

Comparing data obtained from the experiments, the Maha IW7 brake tester provides better results. This is because the roller diameter and the distance between rollers are higher. With a bigger roller diameter, a bigger contact surface between the tyre and the roller is produced. This higher contact surface will produce a lower slippage of the wheel on the roller. Therefore, with lower slippage the MOT brake tester will measure higher values of brake torque to stop the wheel. 
When comparing brake data obtained with Maha IW2 Eurosystem RS2 and IW2 Profy RS5, the first one has $430 \mathrm{~mm}$ of distance between rollers and the second one $400 \mathrm{~mm}$, and both rollers have the same diameter of 202 $\mathrm{mm}$, and higher brake data are obtained with the IW2-RS2 tester. Therefore, it can be said that higher distances between rollers will provide higher brake data when the diameter of the roller of the brake tester is the same.

On the other hand, in Fig. 10, when comparing brake data measured from the rear axis, it can be seen that differences between measures obtained with and without the hole in the vacuum hose are until $14,5 \%$, but between the three Maha testers the difference is $2 \%$.

\section{DaN of brake force of the rear axis of the vehicle Audi A3 measured on the three Mot Maha testers.}

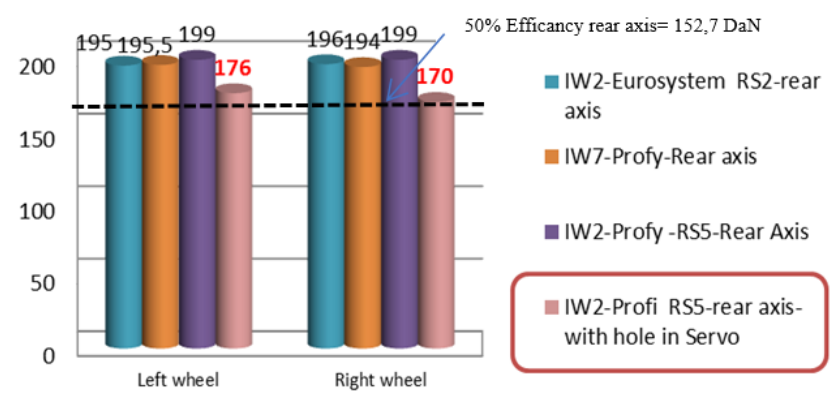

Fig. $10 \mathrm{DaN}$ of brake force of the rear axis of the vehicle measured on the three Mot Maha testers

It can be said that the hole in the servo provides higher differences of brake data measured by the tester IW2RS5 in the rear axis $(14,5 \%)$ than in the front axis $(2,2 \%)$ comparing data with the same experiment without the hole in the servo.

But on the contrary, differences of brake data measured due to the tester characteristics are more notable in front axis measurements $(21,5 \%)$ than in the rear axis $2,5 \%)$. This difference could be due

On the top of that, the Efficiency needed to pass the test is the same for all testers but, as it has been analysed, tester characteristics provides higher efficiency differences than the hole in the vacuum hose.

\section{Conclusions}

When there is a hole in the pipe of the brake booster, and then the pedal is harder to press, this is due to a mechanical issue between the pedal and the master cylinder. But despite, the brake pedal is hard to push the braking system is otherwise functional. Then, the time to press the brake pedal will be much higher. Therefore, the "sight distance" driven during the brake will be much longer. In other words, your vehicle will take longer to stop than normal [15-18]. This can be a short-term problem or a long-term problem depending on the size of the hole. When the stopping distance far exceeds the actual stopping distance under this condition, a hole in the vacuum hose, and the driver is negligent for not repairing the vehicle soon, this could result in danger or even injury.

Comparing the Efficiency, see Fig. 7, the Audi A3 will have $9 \%$ less probability to pass the brake test on a
Maha IW2-RS5 MOT brake tester rather than a IW7 Maha brake tester. However, the vehicle: Audi A3 will have $6 \%$ less probability to pass the exam using the same Maha IW2-RS2 MOT brake tester, with a hole in the vacuum hose of the brake booster. Then, it can be said that brake tester characteristics vary more the measurement than a hole in the vacuum hose of the brake system of the vehicle.

In conclusion, when a vehicle is tested at MOT stations to know if vehicle brakes are in good condition or not, it is not needed a brake test influenced by the MOT brake tester characteristics. It is expected an objective measurement that specifies if the vehicle brake system are in good condition or not. But on the top of that, it is only needed to know if the vehicle will stop safely with the quickest time when an obstacle is founded unexpectedly on the road or not.

With a hole in the vacuum hose, the driver will not stop the vehicle with the shortest "sight distance" when an obstacle is detected. Likewise, with this research, it can be said that the MOT brake tester is not capable to detect a hole in the vacuum hose.

The unique solution to minimize the variability of brake measurements at any MOT station would be to use other type of brake tester verification system without any slippage between the roller and the wheels, and with a sensor on the brake pedal that measures the force needed to depress it. Moreover, all MOT brake testers should have the same characteristics to provide the same results with the same vehicle.

\section{Acknowledgments}

It is thanked the grant: "Ayudas para la realización de Proyectos I+D para grupos de investigación emergentes" GV/2015/034.

\section{References}

1. Ministry of Industry, Tourism and Trade of Spain (2014). CITA. 2014. Standardization of criteria for evaluation of defects diagnosed during the inspection of vehicles at MOT stations. Inspection Procedures Manual.

2. European Community. 2002. Directive 2002/78/EC Official Journal of the European Communities, L 267/23.

3. Ministry of Industry, Tourism and Trade of Spain. 2014. MOT: Inspection Procedures Manual station.

4. Ministry of Industry, Tourism and Trade of Spain 2014. Law No. 29237: National Regulation Vehicle Inspection.

5. Law UNE 82502/2.00: Brake testers allowed at MOT stations.

6. Directive 96/96/CEE: Minimum value of efficiency measured by brake testers at MOT stations.

7. Senabre, C.; Velasco, E.; Valero, S. 2015. Differences in Brake Data Results on Ministry of Transport Roller Bank Testers Such as: Maha, Ryme, with Different Distance between Rollers and Roughness of Rollers, Journal of Mechanics Engineering and Automation 5: 567-572. http://dx.doi.org/: 10.17265/2159-5275/2015.10.005.

8. Senabre, C.; Velasco, E.; Valero, S. 2015. Comparative Analysis of VTEC Bank of Rollers Brake Testers 
versus Maha, Ryme and Dynamometric Platform Testers Used at Ministry of Transport Facilities.

9. Day, A. J. 2014. Braking of Road Vehicles ISBN-10: 0123973147. Publisher: Butterworth-Heinemann.

10. Yasuyuki Kanehira, Yusuke Aoki, Yukio Nishizawa. 2017. Evaluation of an Energy Dissipation Mechanism by Friction for Brake Shims. SAE International Journal of Commercial Vehicles. ISSN 1946-3928.

11. Jorge Soria Galvarro. 2011. Calibration of roller brake testers transmission and use of reference brake force. Report no. 1/2011. NVF Vehicle and Transport. Nordic Road Association.

12. ISO 21069-1. 2004. Road vehicles. Test of braking systems on vehicles with a máximum authorized total mass of over 3,5 t using a roller brake tester. Part 1: Pneumatic braking systems.

13. U.S. Department of Transportation National Highway Traffic Safety Administration Laboratory test procedure for Light Vehicle Brake Systems.

14. García-Pozuelo, D. Modelo de contacto neumáticocalzada a baja Velocidad.

15. Thurston, D. F. 2015. Adhesion considerations in safe brake distance calculations. ASME Joint Rail Conference Mineta Transportat Inst, San Jose, CA. (JRC2015), March 23-26.

16. Thurston, D. F. 2011. Statistical safe braking analysis. ASME/ASCE/IEEE Joint Rail Conference; CO Pueblo; March 16-18. https://doi.org/10.1115/JRC2011-56079.

17. Gao, Zh.; Wang, J.; Wang, D. 2011. Dynamic Modeling and Steering Performance Analysis of Active Front Steering System, Procedia Engineering 15: 1030-1035. https://doi.org/10.1016/j.proeng.2011.08.190.

18. Thurston, D. F. 2011. Statistical safe braking analysis.
ASME/ASCE/IEEE Joint Rail Conference; Pueblo, CO; March 16-18.

https://doi.org/10.1115/JRC2011-56079.

19. Fambro, D.B.; Fitzpatrick, K.; Koppa, R.J. 1997. Determination of Stopping Sight Distance, NCHRP Report 400, TRB, Washington, DC.

C. Senabre, S. Valero, E. Velasco

A HOLE IN THE VACUUM HOSE OF A VEHICLE
PROVIDES LOWER DIFFERENCES IN BRAKE
MEASUREMENTS BY THE MINISTRY OF
TRANSPORT BRAKE TESTERS RATHER THAN THE
CHARACTERISTICS OF THE TESTER USED

S u m m a r y

In this research it is studied how vary brake measurement of a vehicle at Ministry of transport facilities when there is a hole in the vacuum hose of the brake booster. Data of brake with the brake boosting system in bad conditions is compared with results of brake of the same repaired vehicle tested on three different roller bed testers from the Maha brand. Finally, the Efficiency of passing the test with and without the hole in the vacuum hose is calculated to see differences.

Keywords: Ministry of transport; vacuum servo; brake boosting system.

Received May 09, 2017

Accepted April 18, 2018 